TITLE:

\title{
Developing an initial item bank for a new cardiac rehabilitation PROM
}

\section{AUTHOR NAMES AND AFFILIATIONS:}

Dr Aynsley Cowie

Emma Kerr

Dr Janet McKayc

Dr Lesley Allan ${ }^{\mathrm{d}}$

Dr Patricia Thomson ${ }^{\mathrm{e}}$

${ }^{a}$ Consultant Physiotherapist in Cardiology, Cardiac Rehabilitation, Lister Centre, University Hospital Crosshouse, NHS Ayrshire and Arran, Kilmarnock, Scotland KA2 OBE aynsley.cowie@aaaht.scot.nhs.uk

${ }^{\mathrm{b}}$ Assistant Psychologist, Community Forensic Mental Health Team, Ailsa Hospital, NHS Ayrshire and Arran emma.kerr@aapct.scot.nhs.uk

'Consultant Nurse in Cardiac Care, Cardiac Rehabilitation, Lister Centre, University Hospital Crosshouse, NHS Ayrshire and Arran janet.mckay@aaaht.scot.nhs.uk

${ }^{d}$ Psychologist, Acute Psychology Department, West Glasgow Ambulatory Care Hospital, NHS Greater Glasgow and Clyde lesleya.allan@nhs.net

eSenior Lecturer/Co-Director of Masters in Advanced Practice Programme, School of Health Sciences and Sport, University of Stirling patricia.thomson@stir.ac.uk

\section{CORRESPONDING AUTHOR:}

Dr Aynsley Cowie, Cardiac Rehabilitation, Lister Centre, University Hospital Crosshouse, NHS Ayrshire and Arran, Kilmarnock, Scotland KA2 OBE aynsley.cowie@aaaht.scot.nhs.uk, tel. 01563825085

This document is the Accepted Manuscript version of a Published Work that appeared in final form in British Journal of Cardiac Nursing, copyright (c) MA Healthcare, after peer review and technical editing by the publisher. To access the final edited and published work see https://doi.org/10.12968/bjca.2018.13.10.506 


\section{ABSTRACT}

Background: A Scotland-wide government scoping exercise identified the need for a new patient-reported outcome measure (PROM) suitable for the wide range of diagnostic groups now accessing cardiac rehabilitation (CR).

Aim: This paper describes the initial steps underpinning development of the item bank for a first draft tool (PROM-CR1).

Methods: A literature review of existing tools was undertaken to guide a qualitative data collection methodology involving 19 CR staff and 22 service users.

Results: Four conceptual ideas for health/quality of life were identified from the literature review: 'general health', 'physical', 'social' and 'psychological'. Three key qualitative themes, largely reflective of literature review findings, were identified: 'expectations and entitlement', 'adjustment and acceptance' and 'control and choice'.

Future Directions: These data will be combined to form PROM-CR1's initial item bank, which will be piloted with staff and service users and refined to generate a finalised tool (PROM-CR) for use in clinical practice.

Key Words: Patient-reported outcome measures, cardiac rehabilitation, quality of life 


\section{INTRODUCTION}

The Scottish Government's (2014) Heart Disease Improvement Plan advocated modernisation of cardiac rehabilitation (CR) services to meet its 2020 Vision: "All patients with heart disease should be supported by $C R$ to live longer, healthier and independent lives". To facilitate the process, a Scotland-wide scoping exercise was undertaken (Divers, 2015), which found that CR services lack robust outcomes measures.

Patient-reported outcome measures (PROMs) provide validated evidence of health and quality of life (QoL), allowing service users to act as their own 'gold standard', and report upon outcomes that they consider important (Appleby and Devlin, 2010). As PROMs data predict mortality, cardiovascular events, hospitalisation, and cost of care, the scoping exercise recommended that the CR community should define a new PROM to help measure the health impact of rehabilitation (Divers, 2015).

Within the field, there are many different generic and disease-specific health and QoL assessment tools demonstrating varying degrees of validity, reliability and sensitivity (Thompson et al, 2016). None have been tested across the increasing diverse range of diagnostic groups now accessing $\mathrm{CR}$.

Whilst generic PROMs allow comparisons between different medical conditions, they can be too broad to fully assess the impact of one particular illness, however disease-specific PROMs, although more sensitive, can miss broader aspects of a disease (Dempster and Donnelly, 2000). For comprehensive assessment, the current recommendation in CR is to use both a generic and a disease-specific tool, which is both time-consuming and burdensome for service users and clinicians (Thompson et al, 2016).

\section{AIM}

The overall aim of this study was to develop a new CR PROM able to provide robust health status information across a range of cardiac diagnoses. This paper describes 
the initial steps which underpin development of the item bank for the first draft tool (PROM-CR1).

\section{STUDY DESIGN}

This paper describes the first two steps of a seven-step survey design process (Gehlbach et al, 2010). In step one, a literature review was undertaken to identify existing PROMs used within CR, to help establish the overall construct of PROMCR1 and identify initial conceptual ideas of interest. To ensure a critical overview, psychometric properties of these tools were examined (Appleby and Devlin, 2010).

For step two, conceptual ideas identified from the literature review were used to guide a qualitative data collection methodology. Focus groups and individual semistructured interviews were used to ascertain how CR staff and service users verbalise their perceptions of the impact of a cardiac diagnosis upon health and QoL. Focus groups were held first to allow group interactions to stimulate a breadth of comparable and contrasting perceptions (Morgan, 1997; Webb, 2002). These data were explored in more depth within semi-structured interviews, to obtain completeness of data (Morgan, 1997).

Future publications will describe steps three to seven. In steps three and four, qualitative data will be combined with literature review findings to establish PROMCR1's conceptual framework and domains, and the construct indicators informing its initial bank of items. Steps five (expert validation), six (service user interpretation) and seven (piloting for validity and reliability) will describe refinement of a finalised version of the tool (PROM-CR) for use in clinical practice.

\section{STUDY LOCATION AND ETHICAL APPROVAL}

The study was reviewed and approved by the West of Scotland Research Ethics Committee (WoS REC1) [REC ref::15/WS/0151; IRAS project ID:184318], and Research and Development department within NHS Ayrshire and Arran. All participants provided written, informed consent, and all procedures were undertaken within NHS Ayrshire and Arran between February and September 2016 by two 
researchers: a main researcher (consultant physiotherapist with vast clinical and research experience within $\mathrm{CR}$ ), and an assistant researcher (assistant psychologist working within the CR team). They formed a project steering group with a further four clinicians not directly involved in data collection: a cardiac nurse consultant, a cardiologist, a clinical psychologist and a senior nursing lecturer. The study conforms to principles outlined in the Declaration of Helsinki (World Medical Association, 1964).

\section{STEP ONE - LITERATURE REVIEW}

\subsection{Methodology}

A systematic search of the PubMed database was undertaken by the assistant researcher to identify generic and disease-specific PROMs used within CR using the following key words: "health-related quality of life questionnaire" AND "heart" OR "heart disease" OR "cardiac" OR "cardiac rehabilitation". A second search of PubMed was undertaken to identify articles evaluating psychometric properties of the selected tools, using full and abbreviated names of the tools in combination with: "psychometric properties" OR "validity" OR "reliability" OR "sensitivity" OR "development" AND "heart disease" OR "cardiac" or "heart". The entire search methodology was replicated by the main researcher to ensure no key articles were omitted. All duplicates were removed.

To be included in the review, articles were required to meet the following criteria:

- Published in English

- Examining tools:

- measuring more than one domain of health or QoL

- tested in adults (aged $\geq 18$ years) with a cardiac diagnosis initiating CR referral (myocardial infarction [MI], cardiac surgery, percutaneous coronary intervention $[\mathrm{PCl}]$, stable angina pectoris $[\mathrm{AP}]$, arrhythmias, heart failure [HF], or implanted devices) 


\subsection{Results}

As shown in fig. 1a, 14 tools (five generic and nine disease-specific) were identified. Characteristics, measurement domains and the diagnostic groups in which the tools have been tested are shown in table 1. As shown in fig. 1b, 54 articles examining the tools' psychometric properties were identified, and used by the assistant researcher to critique the tools against recognised criteria (Mackintosh et al, 2009). The process was verified by the main researcher. As shown in table 2, across the generic tools, the Medical Outcomes Short Form-36 [SF-36] (Ware and Sherbourne, 1992) met the criteria most closely; certainly, although complicated to score and analyse, the SF-36 is the recommended generic tool for use in CR (Thompson et al, 2016).

Within the disease-specific tools, there was variation across the criteria, and none demonstrated favourable evidence in relation to floor/ceiling effects. The MacNew Heart Disease Quality of Life Tool [MacNew] (Höfer et al, 2004), Kansas City Cardiomyopathy Questionnaire [KCCQ] (Green et al, 2000) and Minnesota Living with Heart Failure Questionnaire [MLHFQ] (Rector et al, 1987) demonstrated most favourable evidence. As the KCCQ and MLHFQ are designed for use in HF, and the MacNew has only been tested in those with a diagnosis of MI or AP, the appraisal confirmed the need for a new PROM which can be applied across a wider range of cardiac diagnoses.

The main and assistant researchers examined the conceptual ideas within the existing tools, for potential use in guiding the qualitative data collection methodology (table 1). They agreed that the most prevalent conceptual ideas ('general health', 'physical', 'social' and 'psychological') should be used as qualitative prompts, but to enable others to emerge, agreed to include an open prompt around 'other factors' influencing health and QoL. 


\section{STEP TWO - QUALITATIVE DATA COLLECTION}

\subsection{Methodology}

\subsubsection{Sample and Recruitment}

6.1.1.1

Staff

By email, the main researcher invited all 61 clinicians and support staff within the cardiology managed clinical network (MCN) in Ayrshire to participate in the focus groups. Of the 17 who expressed interest, 15 were able to attend. Following the groups, a further four staff members from the MCN, purposefully identified to include a range of professions, were invited by the main researcher to participate in individual semi-structured interviews. All four agreed to take part.

\subsubsection{Service Users}

Within NHS Ayrshire and Arran, all CR service users are asked to verbally consent to being added to a CR database which may be accessed by clinicians for correspondence. In batches of 50, the main researcher identified CR service users most recently added to the database, fulfilling the following criteria:

Inclusion Criteria

- Cardiac event (MI, cardiac surgery, PCl, AP, arrhythmia, HF, implanted device) within past six months

- Aged $\geq 18$ yrs

Exclusion Criteria

- Physical/mental impairment realistically preventing data collection

- Documented evidence that service user not informed of diagnosis (e.g. due to physical/mental impairment)

The assistant researcher sent all a letter of invitation with tear-off slip (to confirm/refute interest within two weeks), study information sheet, and SAE. From 
the first two batches of 50 service users (i.e. 100 in total), 28 were willing to participate.

Of the 28 , the first 20 to reply were invited by the assistant researcher by telephone to participate in two initial focus groups and 14 were available to attend. The remaining six agreed to be held in reserve, along with the other eight willing service users - and of those, eight were contacted (purposefully, to include a range of cardiac diagnoses) to participate in semi-structured interviews. All eight agreed. Immediately before every focus group and interview, there was time for further discussion about the study, and for provision of informed, written consent.

\subsubsection{Focus Group Procedures}

All focus groups were held in meeting rooms at clinical sites within NHS Ayrshire and Arran. Staff and service users attended separate focus groups, to enable comparable and contrasting opinions from the two groups to emerge (Webb, 2002). Of the 15 staff recruited, six participated in the first focus group, and nine in the second. Of the 14 service users recruited, seven participated in the first focus group, and seven in the second. The researchers agreed that at least two of each type of group would be held to reduce the possibility of obtaining skewed data from one 'stand alone' group, and that groups would continue to be arranged until there was data saturation (Morgan, 1997).

All focus groups were facilitated by the assistant researcher, whilst the main researcher took notes throughout. Both were familiar to clinicians participating in the groups (beneficial in encouraging the 'flow' of discussion between colleagues), yet had not been involved in the care of any of the service users (ensuring unbiased opinions).

All groups were audio-recorded and all participants were assured that the all discussions would remain anonymous. The assistant researcher began each focus group reiterating the study purpose, and explaining the discussion format and main question to be answered: "How does diagnosis of a cardiac condition impact upon someone's health and QoL?" [staff], or "How has your diagnosis of a cardiac 
condition impacted upon your health and QoL?" [service users]. Initial conceptual ideas identified from the literature review prompted discussions around: perceptions/definitions of general health and QoL, and physical, social, psychological and 'other' factors influencing health and QoL after a cardiac diagnosis. Average focus group duration was 57 minutes (range 49-72 minutes).

\subsubsection{Semi-Structured Interview Procedures}

All individual, semi-structured interviews with four staff and eight $C R$ service users were conducted in meeting rooms at clinical sites within NHS Ayrshire and Arran. All interviews were audio-recorded, and were facilitated by the assistant researcher, who assured participants that all discussions would remain anonymous.

The assistant researcher began every interview reiterating the purpose of the study, and explaining the discussion format and main question to be answered: "How does diagnosis of a cardiac condition impact upon someone's health and QoL?" [staff], or "How has your diagnosis of a cardiac condition impacted upon your health and QoL?" [service users]. As with the focus groups, conceptual ideas identified from the literature review formed the basis of an interview schedule used with both staff and service users, incorporating: perceptions/definitions of general health and QoL, and physical, social, psychological and 'other' factors influencing health and QoL after a cardiac diagnosis.

For staff, the schedule was tailored to each profession, to help different professional perceptions to emerge (as an example, the dietetic schedule is shown in table 3). Within both service user focus groups, participants often discussed the importance of understanding their cardiac diagnoses. To further explore this, an additional question was added to both types of schedule (table 3): "To what extent would you say that it's important for someone to have a good understanding of his/her diagnosis?" [staff], or "To what extent would you say that it is important to have a good understanding of your diagnosis?" [service users]. Average interview duration was 33 minutes (range 25-48 minutes). 


\subsubsection{Qualitative Data Analysis}

After every focus group and interview, the recording was transcribed and the written transcription analysed using a three-stage constant comparison method (Strauss and Corbin, 1999): stage 1 - data chunked into small units and coded, stage 2 codes grouped into categories ('sub-themes'), and stage 3 - 'key themes' identified expressing the content of the codes within sub-themes. This process was undertaken by the assistant researcher and discussed and negotiated with the main researcher. Although the researchers ensured that data analysis of one group/interview did not force the direction of subsequent discussions, data generated contributed to subsequent prompting, where appropriate. This process enabled researchers to identify the need to incorporate the question on understanding a cardiac diagnosis within the interview schedules, and to identify that data saturation had occurred after two of each type (staff and service user) of focus group, and after four staff and eight service user semi-structured interviews.

\subsection{Results}

\subsubsection{Participant Characteristics}

Details of all participants are shown in table 4.

\subsubsection{Summary of Key Themes}

Three key themes (and their sub-themes) identified from the data - 'expectations and entitlement' ('self', 'others'), 'adjustment and acceptance' ('diagnosis', 'lifestyle changes', 'confidence loss') and 'control and choice' ('daily life and health' and 'care') - are shown in table 5, evidenced by relevant quotes from staff and service user participants, and aligned with the prompts (conceptual ideas from the literature review) from which they were most frequently generated. 
Across focus groups and interviews, many staff and service users acknowledged that everyone is entitled to have, and expects, a 'good' QoL, often described as 'feeling well' or being 'in good health'. Many participants discussed expectations that service users place upon themselves after a cardiac diagnosis - how they compare their abilities to undertake everyday tasks and return to work and hobbies, to their pre-diagnosis abilities.

Although only mentioned by a few staff, many service users described frustration and a sense of failure resulting from this constant comparison, and described how perceived expectations of others compound these feelings. Often there was worry around employers' expectations about return to work and job security, and around family and friends treating them differently, causing relationship tensions and feeling burdensome to others.

\subsubsection{Adjustment and Acceptance}

Many service users and staff discussed difficulties in adjusting to, and accepting, a cardiac diagnosis, with several stating that the service user often blames himself/herself, or others. Several staff and service users described how worrying about the impact of the diagnosis, their recovery potential, and the stress that the diagnosis places upon their families and friends, can make them anxious, tearful or depressed. Only the service users verbalised the importance of having 'enough' knowledge and understanding about their condition to help them accept their diagnosis.

Numerous participants discussed the impact of lifestyle changes imposed by a cardiac diagnosis. Many recognised the wide-ranging physically limiting impact cardiac symptoms (pain, shortness of breath, fatigue), altered appetite, poor sleep quality, feeling 'slowed down', and loss of libido - and several staff explained how physical anxiety symptoms are often mistaken for cardiac symptoms - intensifying anxiety symptoms, and causing confidence loss. Several service users described their subsequent apprehension about going out alone, or travelling away from home. 
In addition to imposed lifestyle changes, both staff and service users acknowledged challenges associated with adhering to recommended changes - a healthier diet, smoking less and consuming less alcohol - with many explaining how these can cause social withdrawal, and isolation. Both staff and service users recognised the limiting effect of being unable to maintain a previous role community role, or to drive or work post-diagnosis, with financial constraints caused by loss of earnings further limiting socialisation. Although not mentioned by staff, in addition to anxiety around holiday travel, a few service users verbalised frustration about travel insurance restrictions.

\subsubsection{Control and Choice}

Several staff and many service users recognised the importance of having control and choice; it was considered an entitlement for every person to have control over his/her daily life. Many staff and service users recognised the value of being able to control their preferred daily structure and routine. A few emphasised a desire to be able to change this structure spontaneously, without having to consider the impact upon their condition.

Several service users described their difficulties in adjusting to losing control over their heart and health, and many staff explained how a key goal of CR is to help service users regain this control. Both staff and service users discussed the importance of having 'enough' healthcare support, and several service users highlighted the importance of being able to ask questions to feel involved in their care and more in control of their condition.

\section{DISCUSSION}

This paper describes the first two steps in a seven-step survey process used to create a new PROM for CR. In the first two stages of developing an initial item bank for the first draft (PROM-CR1), a literature review of existing tools was undertaken and its findings used to guide a qualitative data collection methodology. 
The qualitative data were largely reflective of those measured across existing tools. Although several of the reviewed tools (Seattle Angina Questionnaires [SAQ] (Chan et al, 2014; Spertus et al, 1995), Cardiovascular Limitations and Symptoms Profile [CLASP] (Lewin et al, 2002); Chronic Heart Failure Questionnaire [CHQ] (Guyatt et al, 1989) enquire about specific symptoms, in the present study discussions around symptoms were more broad, and experiences varied. This perhaps reflects the wide range of diagnoses of the service user participants, and the fact that staff participants typically care for a diverse range of cardiac conditions.

Of the conceptual ideas identified from existing tools, 'self efficacy and knowledge' (from the KCCQ) and 'disease perception' (from the SAQ) were less prevalent than those selected for use as qualitative prompts, however consistently emerged within service user focus group discussions, and were therefore incorporated within the interviews. It is widely acknowledged that PROMs should not enquire about treatment satisfaction (Appleby and Devlin, 2010), thus this conceptual idea (used within the SAQ) was disregarded after the literature review, and did not emerge within qualitative data, even during discussions around care.

Finally, from the 'Quality of Life Index-Cardiac [QLI-C] (Ferrans and Powers, 1985), neither 'economic' nor 'spiritual' conceptual ideas were considered sufficiently prevalent conceptual ideas for use as qualitative prompts. Whilst economic concerns around finances and returning to work emerged within qualitative data obtained from both staff and service users, spiritual issues were not verbalised at any point.

The mean age and gender split of service users recruited to the qualitative methodology is fairly typical of those attending CR, however within the diagnoses, there was high proportion who had suffered an MI, and no one who had undergone elective $\mathrm{PCl}$ (without prior $\mathrm{MI}$ ). The main and assistant researchers discussed the need to continue to purposefully recruit, however agreed that the range of cardiac diagnoses across those recruited were sufficiently varied to have achieved appropriate data saturation. Certainly, when piloting PROM-CR1, its performance within and across the diagnostic groups will be examined. 


\section{CONCLUSIONS}

In the first two stages of developing a first draft PROM for CR (PROM-CR1), a literature review of existing tools was undertaken and its findings used to guide a qualitative data collection methodology undertaken with CR staff and service users. From the literature, four conceptual ideas for health/QoL were identified: 'general health', 'physical', 'social' and 'psychological'. Qualitative data were organised in three key themes - 'expectations and entitlement', 'adjustment and acceptance', and 'control and choice' - and were largely reflective of literature review findings. These data will be combined to develop an initial item bank for PROM-CR1, which will be tested for validity and reliability, with both staff and service users, and refined to develop a finalised tool (PROM-CR) for use in clinical practice.

\section{KEY MESSAGES}

- A Scotland-wide government scoping exercise identified the need for a new patient-reported outcome measure for use across the wide range of cardiac diagnostic groups now accessing cardiac rehabilitation (CR).

- In the initial stages of developing an bank for a first draft tool (PROM-CR1), a literature review of existing tools was undertaken to identify conceptual ideas to guide a qualitative data collection methodology involving CR staff and service users.

- Four conceptual ideas for health/QoL were identified from the literature review: 'general health', 'physical', 'social' and 'psychological'.

- Qualitative data were organised in three key themes - 'expectations and entitlement', 'adjustment and acceptance', and 'control and choice' - and were largely reflective of the literature review findings.

- These data will be combined and PROM-CR1 piloted with staff and service users to create a finalised version of the tool (PROM-CR) for use in clinical practice. 


\section{REFERENCES}

Appleby J, Devlin, N (2010) Getting the Most out of PROMs - Putting Health Outcomes at the Heart of NHS Decision Making. The King's Fund, London

Bergner, M, Bobbitt RA, Carter WB, Gibson BS (1981) The Sickness Impact Profile: Development and final revision of a health status measure. Medical Care; 19:787-805

British Association for Cardiovascular Prevention and Rehabilitation (2017) Standards and Core Components for Cardiovascular Disease Prevention and Rehabilitation. BACPR, London

Chan PS, Jones PG, Arnold SA, Spertus JA (2014) Development and validation of a short version of the Seattle Angina Questionnaire. Circulation: Cardiovascular Quality and Outcomes; 7(5):640-7

Dempster M, Donnelly M (2000) Measuring the health related quality of life of people with ischaemic heart disease. Heart; 83:641-644

Divers F (2015) Scoping of Cardiac Rehabilitation Services in Scotland 2015. Scottish Government, Edinburgh

Dunderdale K, Thompson DR, Beer SF, Furze G, Miles JNV (2008) Development and validation of a patient-centred health-related quality of life measure: the chronic heart failure assessment tool. Journal of Cardiovascular Nursing; 23(4): 364-70

Ferrans C, Powers M (1985) Quality of Life Index: Development and psychometric properties. Advances in Nursing Science; 8:15-24

Gehlbach H, Artino AR, Durning (2010) Survey development guidance for medical education researchers. Academic Medicine; 85:925

Green PC, Porter CB, Bresnahan DR, Spertus JA (2000) A development and evaluation of the Kansas City Cardiomyopathy Questionnaire: A new health status measure for heart failure. Journal of the American College of Cardiology; 35(5): 1245-55 
Guyatt GH, Nocradi S, Halcrow S, Singer J, Sullivan MJJ, Fallen EL (1989) Development and testing of a new measure of health status for clinical trials in heart failure. Journal of General Internal Medicine; 4:101-7

Höfer S, Lim L, Guyatt G, Oldridge N (2004) The MacNew Heart Disease health-related quality of life instrument: a summary. Health and Quality of Life Outcomes; 2(3):1-8

Hunt SM, McEwan J, McKenna SR (1985) Measuring health status: a new tool for clinicians. Journal of the Royal College of General Practitioners; 35:185-88

Lewin RJP, Thompson DR, Martin CR, Stuckey N, Devlen J, Michaelson S, Maguire P (2002) Validation of the Cardiovascular Limitations and Symptoms Profile (CLASP) in chronic stable angina. Journal of Cardiopulmonary Rehabilitation; 22:184-91

Mackintosh A, Gibbons E, Fitzpatrick R (2009) A Structured Review of Patient Reported Outcome Measures for People with Heart Failure: An Update. Department of Public Health Oxford.

Morgan DL (1997) Focus Groups as Qualitative Research, 2nd Edition. SAGE Publications, California

Rector T, Kubo SH, Cohn JN (1987) Patients' self-assessment of their congestive heart failure, part 2: Content, reliability and validity of a new measure, the Minnesota Living with Heart Failure Questionnaire. Heart Failure; 3:198-209

Scottish Government (2014) Heart Disease Improvement Plan. Scottish Government, Edinburgh

Spertus JA, Winder JA, Dewhurst TA, Deyo RA, Prodzinski J, McDonnell M, Fihn SD (1995) Development and evaluation of the Seattle Angina Questionnaire: a new functional status measure for coronary artery disease. Journal of American College of Cardiology; 25:333-41

Strauss A, Corbin J (1999) Basics of Qualitative Research. Techniques and Procedures for Developing Grounded Theory, 2nd Edition. SAGE Publications, Newbury Park

The Euro-Qol Group (1990) Euro-QoL- a new facility for the measurement of health related quality of life. Health Policy; 16:199-206

Thompson DR, Ski CF, Garside J, Astin F (2016) A review of health-related quality of life patient reported outcome measures in cardiovascular nursing. European Journal of Cardiovascular Nursing; 15(2):114-25

Ware J, Kosinski M, Keller SD (1996) A 12-Item Short-Form Health Survey: Construction of scales and preliminary tests of reliability and validity. Medical Care; 34(3):220-33

Ware JE, Sherbourne CD (1992) The MOS-36 Item Short Form Health Survey (SF-36): Conceptual framework and item selection. Medical Care; 30(6): 473-83

Webb B (2002) Using focus groups as a research method: A personal experience. Journal of Nursing Management, 10:27-35

World Medical Association (1964) Human Experimentation Code of Ethics of the World Medical Association - Declaration of Helsinki. British Medical Journal; 2(5402):17 
Fig. 1a: Identification of Generic and Disease-specific Tools

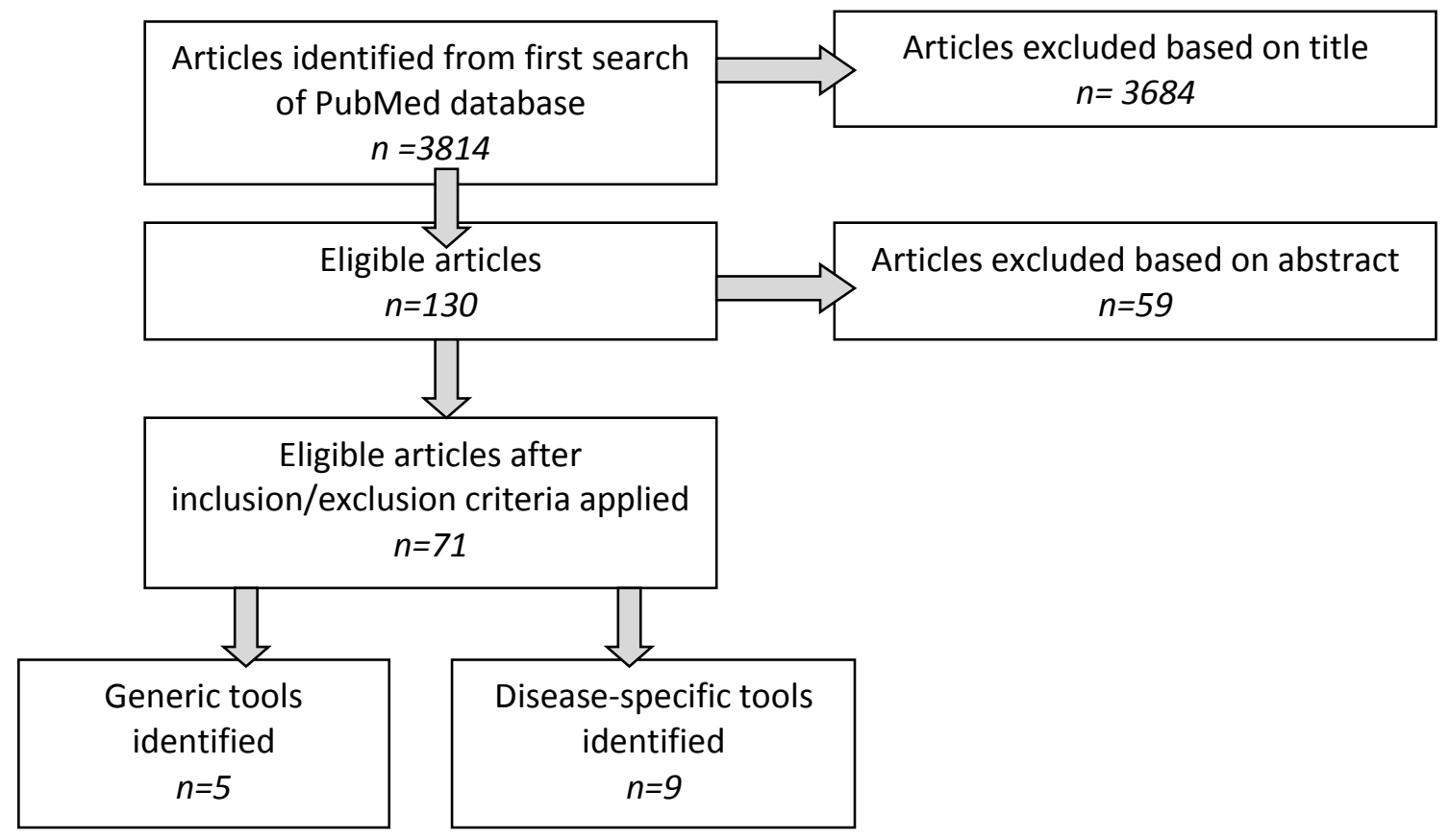

Fig. 1b: Examination of Psychometric Properties of Selected Tools

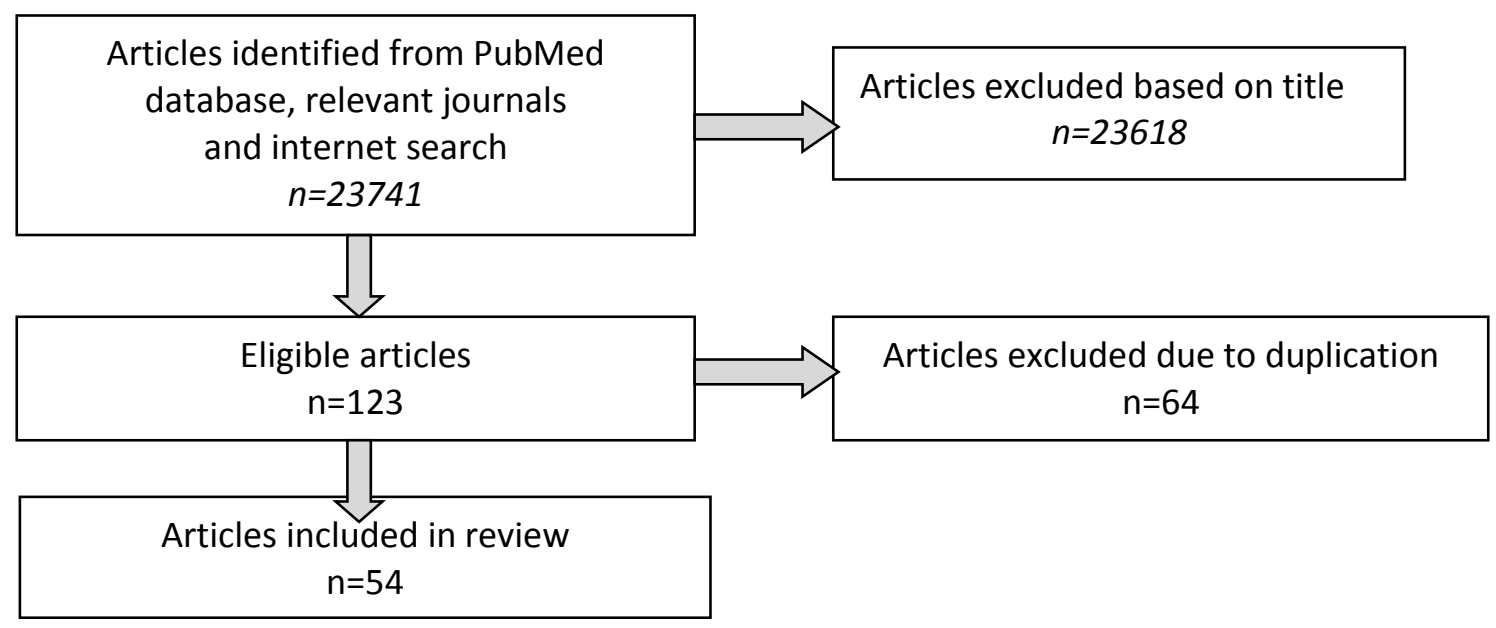




\begin{tabular}{|c|c|c|c|c|c|}
\hline $\begin{array}{l}\text { PROM } \\
\text { NAME }\end{array}$ & $\begin{array}{l}\text { Number of } \\
\text { Items }\end{array}$ & $\begin{array}{l}\text { Recall } \\
\text { Period }\end{array}$ & $\begin{array}{l}\text { Method of } \\
\text { Administration }\end{array}$ & $\begin{array}{c}\text { Measurement Domains } \\
{[\rightarrow \text { Conceptual Ideas Identified from Measurement Domains*] }}\end{array}$ & $\begin{array}{c}\text { Target } \\
\text { Populations }\end{array}$ \\
\hline SF-36 & 36 & $4 \mathrm{wks}$ & Self or interviewer & $\begin{array}{l}8 \text { - Vitality, Physical Function, Bodily Pain, General Health, Role-Physical, Role-Emotional, Role-Social, Mental Health } \\
{[\rightarrow \text { General Health; Physical; Psychological/Emotional; Social] }}\end{array}$ & Generic \\
\hline SF-12 & 12 & $4 \mathrm{wks}$ & Self or interviewer & $\begin{array}{l}8 \text {-Vitality, Physical Function, Bodily Pain, General Health, Role-Physical, Role-Emotional, Role-Social, Mental Health } \\
{[\rightarrow \text { General Health; Physical; Psychological/Emotional; Social] }}\end{array}$ & Generic \\
\hline EQ-5D & 5 & Today & Self & $\begin{array}{l}5 \text { - Mobility, Self Care, Usual Activity, Pain \& Discomfort, Anxiety \& Depression (+ Global Health Rating) } \\
{[\rightarrow \text { Global Health; Physical; Psychological] }}\end{array}$ & Generic \\
\hline NHP & 45 & At this moment & Self or interviewer & $\begin{array}{l}5 \text { - Physical Mobility, Social Isolation, Emotional Reactions, Pain, Sleep \& Energy } \\
{[\rightarrow \text { Physical; Psychological/Emotional; } \text { Social] }}\end{array}$ & Generic \\
\hline SIP & 136 & Today & Self or interviewer & $\begin{array}{l}2 \text { - Physical, Psychosocial } \\
{[\rightarrow \text { Physical; Psychological] }}\end{array}$ & Generic \\
\hline MacNew & 27 & $2 w k s$ & Self & $\begin{array}{l}3 \text { - Physical, Emotional, Social } \\
{[\rightarrow \text { Physical; Emotional; Social] }}\end{array}$ & MI or AP (attending CR) \\
\hline SAQ & 19 & $4 \mathrm{wks}$ & Self & $\begin{array}{l}5 \text { - Physical Limitation, AP Stability, AP Frequency, Treatment Satisfaction, Disease Perception } \\
{[\rightarrow \text { Physical; Treatment Satisfaction; Disease Perception] }}\end{array}$ & $\mathrm{AP}, \mathrm{MI}, \mathrm{PCl}$, cardiac surgery \\
\hline SAQ-7 & 7 & 4 wks & Self & $\begin{array}{l}3 \text { - Physical Limitation, AP Frequency, Quality of Life } \\
{[\rightarrow \text { Physical] }}\end{array}$ & $\mathrm{AP}, \mathrm{MI}, \mathrm{PCl}$, cardiac surgery \\
\hline CLASP & 37 & 2 wks & Self & $\begin{array}{l}2 \text { - Symptoms, Functional Limitations } \\
{[\rightarrow \text { Physical] }}\end{array}$ & CHD, AP \\
\hline $\mathrm{CHQ}$ & 20 & $4 \mathrm{wks}$ & Interviewer & $\begin{array}{l}3 \text { - Dyspnoea, Fatigue, Emotional Function } \\
{[\rightarrow \text { Physical; Emotional] }}\end{array}$ & $\mathrm{HF}$ \\
\hline KCCQ & 23 & 2 wks & Self & $\begin{array}{l}5 \text { - Physical Function, Symptoms, Social Function, Self-efficacy \& Knowledge, Quality of Life } \\
{[\rightarrow \text { Physical; Social; Self-efficacy \& Knowledge; Quality of Life] }}\end{array}$ & $\mathrm{HF}$ \\
\hline MLHFQ & 21 & $1 \mathrm{mth}$ & Self & $\begin{array}{l}2 \text { - Physical, Emotional } \\
{[\rightarrow \text { Physical; Emotional] }}\end{array}$ & $\mathrm{HF}$ \\
\hline CHAT & 46 & $2 w k s$ & Self & $\begin{array}{l}4 \text { - Symptoms, Activity Levels, Psychosocial, Emotions } \\
{[\rightarrow \text { Physical; Emotional] }}\end{array}$ & $\mathrm{HF}$ \\
\hline QLI-C & 36 & Now & Self & $\begin{array}{l}4 \text { - Health \& Functioning, Psychological/Spiritual, Social \& Economic, Family (+Quality of Life Overall) } \\
{[\rightarrow \text { Health; Physical; Psychological \& Spiritual; Social \& Economic; Quality of Life] }}\end{array}$ & All with cardiac diagnosis \\
\hline
\end{tabular}




\begin{tabular}{|c|c|c|c|c|c|c|c|c|c|c|c|c|c|c|}
\hline Appraisal Criteria & SF-36 & SF-12 & EQ-5D & NHP & SIP & MacNew & SAQ & SAQ-7 & CLASP & CHQ & KCCQ & MLHFQ & CHAT & QLI-C \\
\hline Test-retest Reliability & + & 0 & + & 0 & + & + & + & ++ & + & 0 & ++ & + & 0 & + \\
\hline Internal Consistency & ++ & 0 & 0 & + & + & +++ & + & 0 & 0 & + & ++ & +++ & + & + \\
\hline Content Validity & + & + & ++ & + & + & ++ & + & + & 0 & +++ & +++ & + & +++ & - \\
\hline Construct Validity & + & + & ++ & + & + & ++ & + & ++ & + & + & ++ & ++ & + & 0 \\
\hline Sensitivity/Responsiveness & + & + & - & - & + & + & + & + & + & + & + & ++ & 0 & - \\
\hline Floor/Ceiling Effects & - & 0 & - & - & 0 & - & - & 0 & 0 & 0 & - & - & 0 & 0 \\
\hline Acceptability & ++ & 0 & ++ & ++ & 0 & + & + & + & + & 0 & + & +++ & 0 & 0 \\
\hline Burden & + & ++ & ++ & ++ & - & ++ & + & ++ & + & 0 & + & + & 0 & 0 \\
\hline
\end{tabular}

Table 2: Appraisal of Existing Tools' Psychometric Properties Adapted from Mackintosh et al (2009)

$[-$, evidence does not support criteria; 0 , not reported or no evidence in favour; + , some limited evidence in favour; ++ , some good evidence in favour, but some aspects do not meet criteria or are unreported; +++, good evidence in favour; SF-36, Medical Outcomes Short Form-36 (Ware et al, 1992; SF-12, Shortened 12-item version of Medical Outcomes Short Form-36 (Ware et al, 1996); EQ-5D, EuroQoL-5D (The EuroQoL Group, 1990); NHP, Nottingham Health Profile (Hunt et al, 1985); SIP, Sickness Impact Profile (Bergner et al, 1981); MacNew, MacNew Heart Disease Quality of Life Tool (Höfer et al, 2004); SAQ Seattle Angina Questionnaire (Spertus et al, 1995); SAQ-7, Shortened 7-item Version of SAQ (Chan et al, 2014); CLASP, Cardiovascular Limitations and Symptom Profile (Lewin et al, 2002); CHQ, Chronic Heart Failure Questionnaire (Guyatt et al, 1989); KCCQ, Kansas City Cardiomyopathy Questionaire (Green et al, 2000); MLHFQ, Minnesota Living with Heart Failure Questionnaire (Rector et al, 1987); CHAT, Chronic Heart Failure Assessment Tool (Dunderdale et al, 2008); QLI-C, Quality of Life Index - Cardiac (Ferrans and Powers, 1985); MI, myocardial infarction; AP, angina pectoris; CR, cardiac rehabilitation; PCI, percutaneous coronary intervention; CHD, coronary heart disease; $H F$, heart failure; VAS, visual analogue scale; wks, weeks; mth, month 


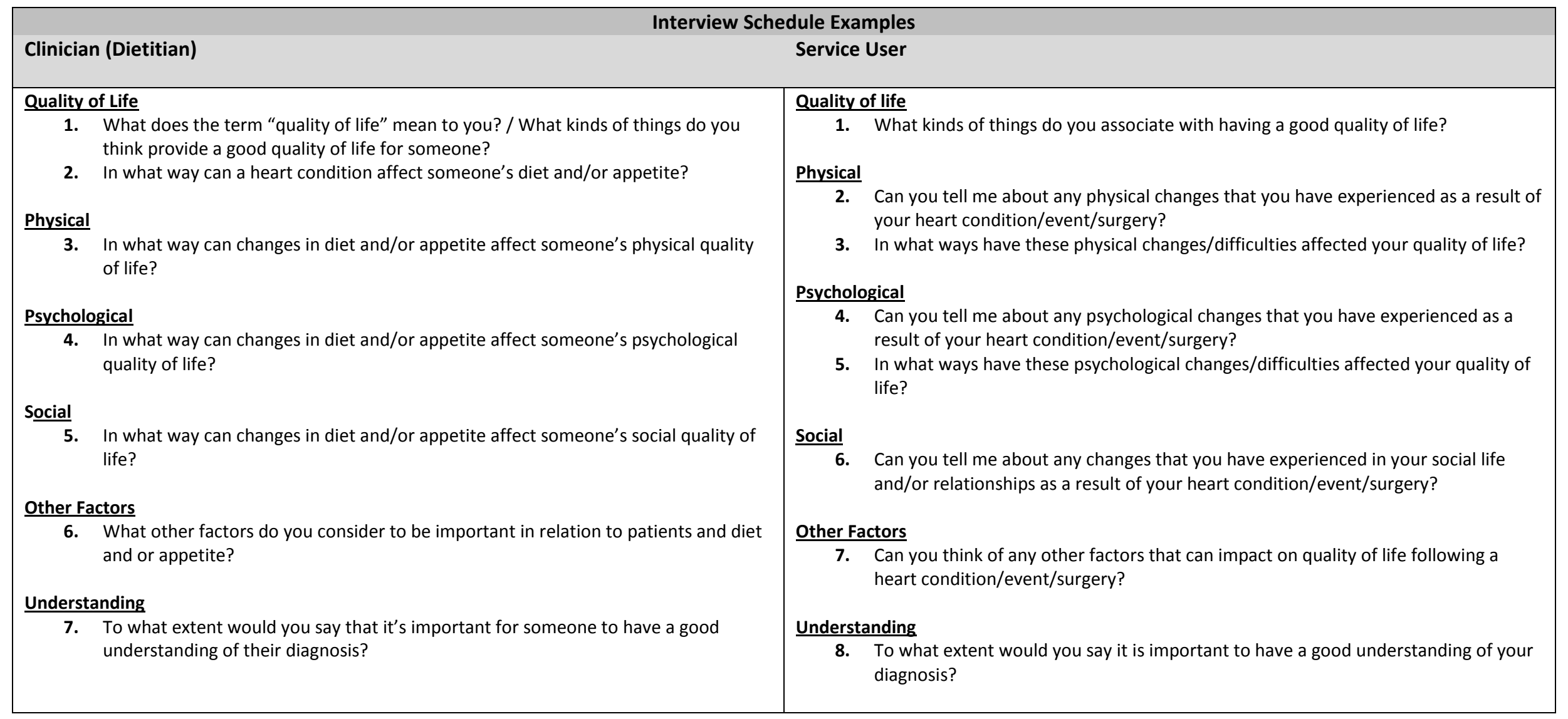

Table 3: Example Interview Schedules - Clinician (Dietitian) and Service User 


\begin{tabular}{|l|}
\hline Participant Characteristics \\
\hline Focus Group 1 - Staff ( $n=6$ ) \\
CR Nurses - 4; HF Nurses - 1; Physiotherapist - 1 \\
Focus Group 2 - Staff ( $n=9$ ) \\
CR Nurses - 4; HF Nurses - 4; Medical Secretary - 1 \\
Interviews 1-4 - Staff ( $n=4$ ) \\
Dietitian - 1; Clinical Psychologist - 1; Physiotherapist - 1; CR Nurse - 1 \\
\hline Focus Group 3 - Service Users ( $n=6$ ) \\
Mean age: 66yrs (range 62-84yrs); 4 males / 3 females \\
Referring Diagnoses \\
MI - 6, with: Previous history of AP - 2, PCI post-MI - 3, Defibrillator \\
implanted post-MI - 1, Pacemaker in situ - 1, HF (ischaemic) - 1 \\
Focus Group 4 - Service Users ( $n=6$ ) \\
Mean age 68yrs (range 64-86yrs); 6 males / 1 female \\
Referring Diagnoses \\
MI - 7, with: Previous history of AP - 2, PCI post-MI - 3, Defibrillator \\
implanted post-MI - 1 \\
Interviews 5-12 - Service Users ( $n=8$ ) \\
Mean age 68yrs (range 54-79yrs); 5 males / 3 females \\
Referring Diagnoses \\
MI - 5, with: Previous valve surgery - 1, PCI post-MI - 2, CABG post-MI - \\
2, Arrhythmia (atrial fibrillation) - 1, HF (dilated cardiomyopathy) - 1
\end{tabular}

Table 4: Participant Characteristics

[CR, cardiac rehabilitation; $H F$, heart failure; $A P$, angina pectoris;

$P C I$, percutaneous coronary intervention; $C A B G$, coronary artery bypass graft surgery] 


\begin{tabular}{|c|c|c|c|}
\hline $\begin{array}{l}\frac{\text { Literature }}{\text { Review }} \\
\text { Conceptual } \\
\text { Idea }\end{array}$ & $\begin{array}{c}\text { Qualitative D } \\
\text { Key } \\
\text { Theme }\end{array}$ & $\begin{array}{l}\text { Sub- } \\
\text { Theme }\end{array}$ & Staff and / or Service User Quotes to Evidence: \\
\hline $\begin{array}{l}\text { General health } \\
\text { and QoL }\end{array}$ & \multirow{9}{*}{$\begin{array}{l}\text { Expectations } \\
\text { and } \\
\text { Entitlement }\end{array}$} & \multirow[t]{5}{*}{ Self } & It's just about generally feeling well" [FG1, staff]; "Overall, feeling like you're in good health" [FG3, su] \\
\hline Physical & & & "They need to be able to carry out everyday activities" [10, staff]; "You are limited doing just simple, everyday activities" [FG3, su] \\
\hline Physical & & & $\begin{array}{l}\text { "Engaging in the things they enjoy" [FG1, staff] } \\
\text { "Doing your hobbies...being able to engage fully" [FG4, su]; "I would like to do the things I enjoy from before" [I6, su] }\end{array}$ \\
\hline Psychological & & & "There's also frustration about limitations" [FG2, staff]; "I get frustrated about what I can physically do" [FG3, su] \\
\hline Psychological & & & "He felt like he'd failed and he was disappointed" [FG1, staff]; "I just had this sense of being a failure" [FG4, su] \\
\hline Psychological & & \multirow[t]{4}{*}{ Others } & $\begin{array}{l}\text { "People are often anxious about pressures upon them to return to work...and financially" [FG2, staff] } \\
\text { "I was off work and didn't know if I was going to get back or not. It was a worrying time, without that security" [13, su] }\end{array}$ \\
\hline Social & & & $\begin{array}{l}\text { "They [partner] can end up smothering you" [FG3, su]; "I think the family wrap them in cotton wool" [FG1, staff] } \\
\text { "You almost get a bit of celebrity status with friends" [15, su]; "Once you're home, friends kind of ignore you" [FG3, su] }\end{array}$ \\
\hline Social & & & $\begin{array}{l}\text { "You feel like you're annoying each other, being at home" [FG3, su]; Tensions within the family" [FG2, staff] } \\
\text { "Friends would really annoy me, and I felt I annoyed them" }[13, \mathrm{su}]\end{array}$ \\
\hline Psychological & & & "Feeling of being a burden to other people" [FG2, staff]; "You can feel a bit like a burden" [FG3, su] \\
\hline Psychological & \multirow{15}{*}{$\begin{array}{l}\text { Adjustment } \\
\text { and } \\
\text { Acceptance }\end{array}$} & \multirow[t]{6}{*}{ Diagnosis } & "They might blame themselves as well, you know" [FG1, staff] "What did I do wrong? There must have been something" [I3, su] \\
\hline Psychological & & & $\begin{array}{l}\text { "I think sometimes for them to move past that diagnoses, it's hard...they end up too scared to kind of...move on" [FG2, staff]; } \\
\text { "I just worry - what's ahead, will it get worse, what to expect" [I1, su] }\end{array}$ \\
\hline Social & & & "The family will often experience stress" [FG2, staff] "It does cause stress, on your husband or wife, your family and your friends. Everyone feels it" [FG3, su] \\
\hline Psychological & & & "I just burst out crying...and that's not me" [FG3, su]; "I'm much more tearful, weepier. It happens all the time [II, su] \\
\hline Psychological & & & "They just feel down" [110, staff]; "You feel down, you feel depressed" [FG4, su] \\
\hline Other & & & "Understanding your own diagnosis is important [FG3, su]; "Because I have enough knowledge, I feel better" [I2, su] \\
\hline Physical & & \multirow[t]{6}{*}{$\begin{array}{l}\text { Lifestyle } \\
\text { Changes }\end{array}$} & $\begin{array}{l}\text { "Chest pain...breathlessness...fatigue" [FG2, staff]; "That pain in my chest" [FG3, su] } \\
\text { "You're halfway through something and short of breath" [FG3, su]; "When I do anything, fatigue floors me" [FG4, su] }\end{array}$ \\
\hline Physical & & & "You find that...they're not eating enough to keep well" [FG1, staff]; "My appetite has altered hugely" [I1, su] \\
\hline Physical & & & "Getting enough sleep is very important" [FG1, staff]; "My biggest problem was sleep. Or lack of" [FG3, su] \\
\hline Physical & & & "They certainly talk about being 'slowed down'" [I10, staff]; "It's a slowing down. You feel it." [FG3, su] \\
\hline Physical & & & "Reduced sex drive can be an issue" [FG2, staff]; "Sexually.. just don't feel like it" [17, su] \\
\hline Psychological & & & $\begin{array}{l}\text { "They pick up on lots of symptoms that's......exaggerated by the presence of actual cardiac symptoms" [I11, staff]; } \\
\text { "You're aware of your own heart beat" [FG3, su]; "Feeling tense, all over. Your muscles" [I6, su] }\end{array}$ \\
\hline Psychological & & \multirow[t]{3}{*}{$\begin{array}{l}\text { Confidence } \\
\text { Loss }\end{array}$} & $\begin{array}{l}\text { "It can have a huge impact not only actual ability to do things but perceived ability as well" [I11, staff] } \\
\text { "I spent time thinking - 'can I really do this?'" [FG3, su]; "I had no confidence in what I could do daily" [I2, su] }\end{array}$ \\
\hline Psychological & & & $\begin{array}{l}\text { "It affects your willingness to travel anywhere...especially on your own....even out of the house" [FG4, su] } \\
\text { "Back then, I would never been able to say that I'm going out on my own". [I2, su] }\end{array}$ \\
\hline Psychological & & & $\begin{array}{l}\text { "I'm afraid to go on holiday abroad, that's one that bothers me, flying to the sun. I worry about the hassle at the airport." [FG4, su]; } \\
\text { "Travel is certainly an issue - it makes you anxious" [FG4, su] }\end{array}$ \\
\hline
\end{tabular}




\begin{tabular}{|c|c|c|c|}
\hline Social & & $\begin{array}{l}\text { Lifestyle } \\
\text { Changes }\end{array}$ & $\begin{array}{l}\text { "The lifestyle changes are hard....a healthier diet.." [FG1, staff] } \\
\text { "I think change in diet as well...cutting out the things that you really like...it's a struggle" [FG3, su] }\end{array}$ \\
\hline Social & & & "They struggle with things like....stopping smoking" [FG1, staff]; "I've stopped smoking... which is so hard." [FG3, su] \\
\hline Social & & & $\begin{array}{l}\text { "They have to restrict their drinking...alcohol...and that affects their social lives" [FG1, staff]* } \\
\text { "My friends are drinkers..so I don't see them as much now" [FG4, su]* }\end{array}$ \\
\hline Social & & & $\begin{array}{l}\text { "Socially they limit things because it's often difficult" [I10, staff] } \\
\text { "After the heart problem, everything just stopped socially" [FG3, su] }\end{array}$ \\
\hline Social & & & "Withdrawing from activities...is common" [I11, staff]; "You can feel quite isolated really" [FG3, su] \\
\hline Social & & & $\begin{array}{l}\text { "They can lose that sense of community role" [FG2, staff]; "The concept of self...and role is compromised" [I11, staff] } \\
\text { "I used to cut my neighbour's grass and now I can hardly cut my own! That's hard to come to terms with... [FG3, su] }\end{array}$ \\
\hline Physical & & & "They often talk about not being able to drive" [FG1, staff]; "I couldn't drive for months and that was a bind" [FG3, su] \\
\hline Physical & & & "Not being able to work, that's hard for them" [FG2, staff]; "I just wanted to be able to earn again" [FG3, su] \\
\hline Social & & & $\begin{array}{l}\text { "The drop in money... then links in with the social thing, you get invited but can't afford to go" [FG3, su] ; } \\
\text { "Being financially constrained is such an issue" }[15, \text { su]; }\end{array}$ \\
\hline Social & & & $\begin{array}{l}\text { "Being restricted to travel... the hardest. Travel insurance" [I1, su] } \\
\text { "I have returned to travelling again, but insurance costs are so restricting" [14, su] }\end{array}$ \\
\hline Physical & $\begin{array}{l}\text { Control and } \\
\text { Choice }\end{array}$ & $\begin{array}{l}\text { Daily Life } \\
\text { and Health }\end{array}$ & $\begin{array}{l}\text { "I think they just want to be able to get back to their own day-to-day structure and routine" [FG3, staff] } \\
\text { "I just really wanted to get back to my old routine" }[19, \text { su] }\end{array}$ \\
\hline Physical & & & $\begin{array}{l}\text { "Doing what you want, spontaneously" [FG1, staff] } \\
\text { "You just can't go out and do anything spontaneously" [FG3, su]; "You have to plan everything out now" [FG4, su] }\end{array}$ \\
\hline Psychological & & & $\begin{array}{l}\text { "It's important to give them more control"[FG1, staff] } \\
\text { "The feeling that I couldn't control my own condition" [FG4, su]; "It was difficult to lose control of my body" [I3, su] }\end{array}$ \\
\hline Psychological & & Care & $\begin{array}{l}\text { "They really value the support from staff...just someone to speak to" [FG1, staff] } \\
\text { "Everyone needs a different amount of support." [FG4, su] }\end{array}$ \\
\hline Other & & & $\begin{array}{l}\text { "The biggest thing for me has been accessing information - being able to ask questions" [I1, su] } \\
\text { "You want to ask for answers about wrong with you" [FG4, su] }\end{array}$ \\
\hline Other & & & $\begin{array}{l}\text { "They want to take active role in their recovery as well, and not just do what they've been told to do" [FG1, staff\} } \\
\text { "You want to make decisions on your care and treatment" [FG4, su] }\end{array}$ \\
\hline
\end{tabular}

\section{Table 5: Qualitative Data Aligned with Conceptual Ideas Obtained from Literature Review}

[Quotes are displayed in "...." followed by [Focus Group (FG) or Interview (I) Number, and 'staff' (for staff quotes) or 'su' (for service user quotes); Bold type, staff quote; Focus group and interview numbers are only provided to show the spread of data obtained across all participants - i.e. they are not intended to enable attribution of a quote to a particular individual; For clarity, qualitative data are presented in the order in which they are described within the main text, therefore the 'lifestyle changes' sub-theme is split] 